Prepared as part of the

Greater Everglades Priority Ecosystems Science Initiative

\title{
Hydrogeology and Aquifer Storage and Recovery Performance in the Upper Floridan Aquifer, Southern Florida
}

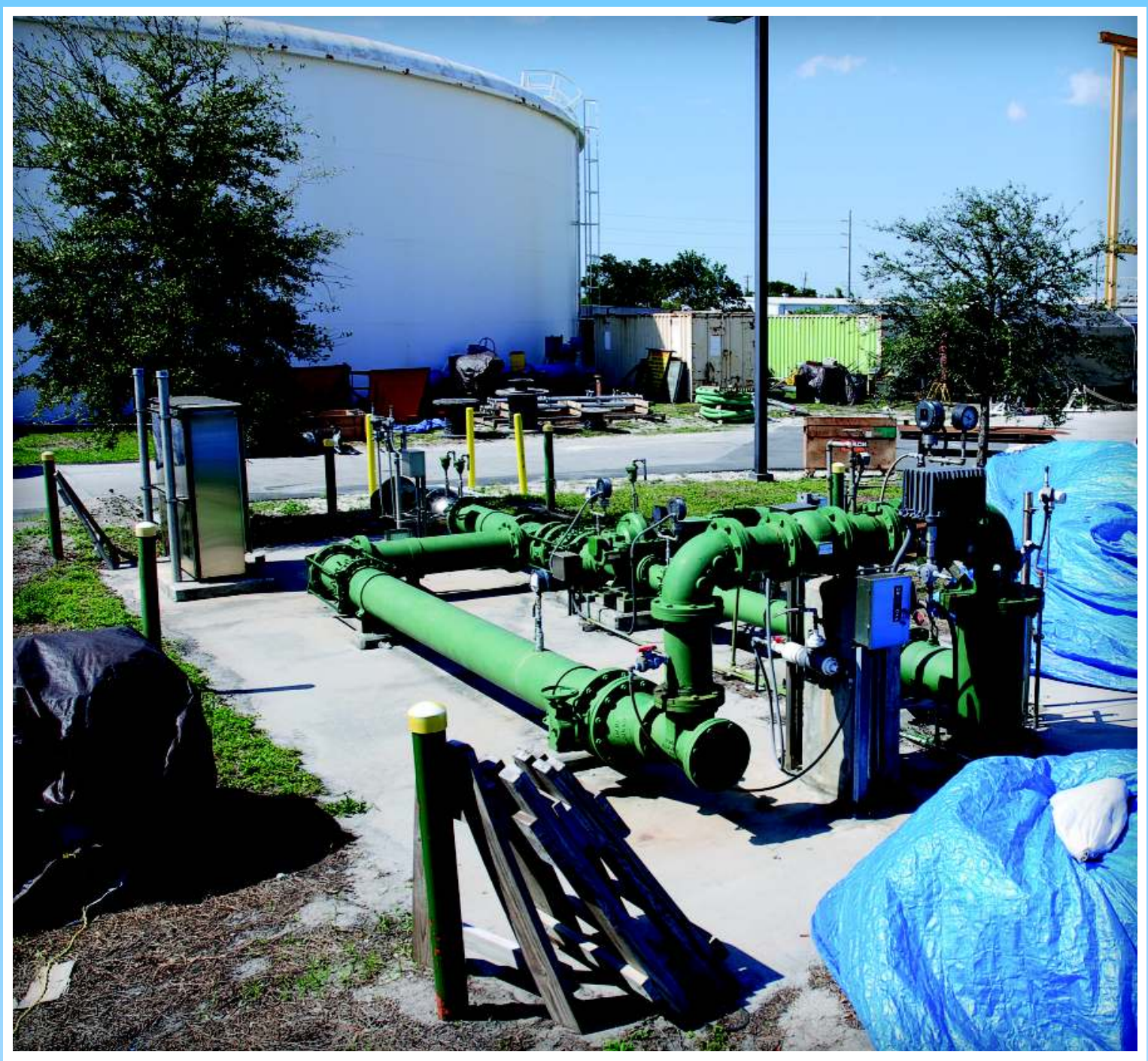

Scientific Investigations Report 2006-5239

U.S. Department of the Interior 